\title{
Recovery from a Critical Disaster and Sustainable Conservation Management for Chum Salmon under a Warming Climate on the Sanriku Coast, Japan
}

\author{
Masahide Kaeriyama $^{1}$, Yuichi Shimizu ${ }^{2}$, Yuki Minegishi ${ }^{3}$, and Jun Aoyama ${ }^{3}$ \\ ${ }^{1}$ Arctic Research Center, Hokkaido University, N21 W11, Kita-ku, Sapporo 001-0021, Japan \\ ${ }^{2}$ Iwate Fisheries Technology, 3-75-3 Heita, Kamaishi, Iwate 026-0001, Japan \\ ${ }^{3}$ International Coastal Research Center, Atmosphere and Ocean Research Institute, The University of Tokyo, \\ Akahama 1-19-8, Otsuchi, Iwate 028-1102, Japan
}

Keywords: chum salmon, GEJE, TEAMS, Salmon Café, global warming, Jomon period, Sanriku Coast

The 2011 Great East Japan Earthquake (GEJE) and tsunami caused immense damage to the Sanriku Coast in northeastern Honshu, Japan. After this catastrophic disaster, the Tohoku Ecosystem-Associated Marine Science (TEAMS) research program was formed. The objectives of this paper are to introduce valuable research results from TEAMS and to clarify the impact of global warming on chum salmon, which is a further threat after the GEJE. For the last ten years, a lot of researchers and scientists contributed to various salmon research fields, including salmon ecology and physiology, oceanology, genetics, the economy, and salmon ethnology for restoring salmon production, coastal and lower freshwater ecosystems, the fisheries industry, salmon hatchery programs, and regional-human communities (Table 1). Research results were immediately provided to the Salmon Café as outreach and published in the proceedings of Salmon Café every year since 2013 (Fig. 1).

Table 1. Main results of chum salmon research from the Tohoku Ecosystem-Associated Marine Science (TEAMS) program.

- Life-history strategy of juvenile chum salmon in rivers and sea of the Sanriku Coast

- Temporal-spatial change in the distribution of juvenile chum salmon eDNA on the Sanriku Coast

- Predation effect of seabirds on hatchery-stocked juvenile chum salmon

- Temperature tolerability and seawater adaptability of juvenile chum salmon

- Ontogeny and developmental stage of juvenile chum salmon

- Population dynamics of chum salmon returning to the Sanriku Coast

- Physiology and migration behavior of adult chum salmon

- Genetic population structure of Sanriku chum salmon

- Wild population and natural spawning of Sanriku chum salmon

- Oceanological characteristic of the Sanriku Coast using the WebGIS

- Salmon ethnology on the Sanriku Coast

- Fisheries industry and food processing of salmon

- Food processing of salmon

- Fish disease of chum salmon

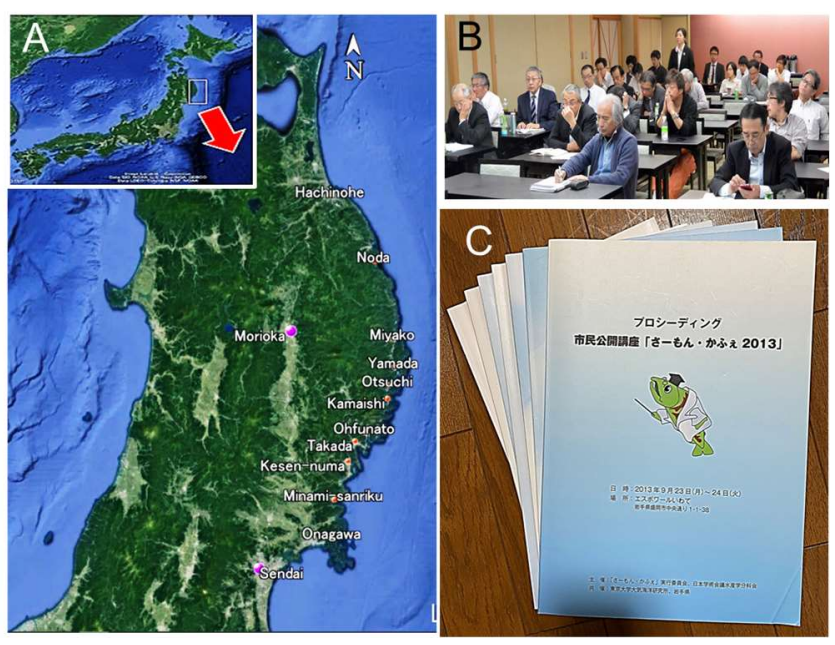

Fig. 1. Sanriku Coast on northern Honshu Island, Japan (A), Salmon Café (B), and Proceedings of the Salmon Café (C). 


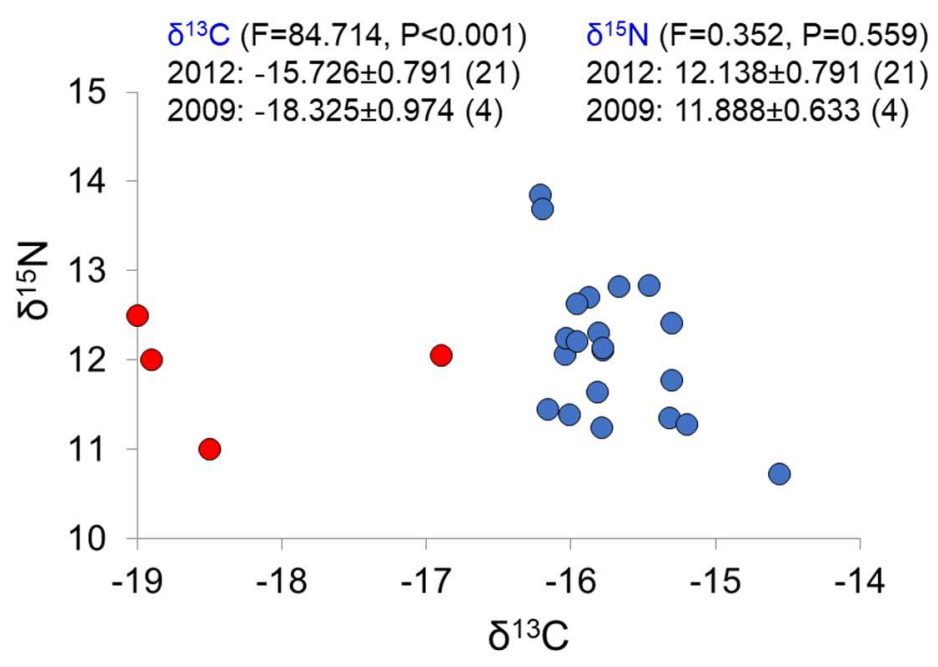

Fig. 2. Carbon and nitrogen stable isotope of juvenile chum salmon on the Sanriku Coast before $(2009 ; \bullet)$ and after $(2012 ; \bullet)$ the tsunami (Qin et al. 2016).

First, we introduce some results of important salmon research. Qin et al. (2016) clarified the carbon and nitrogen stable isotope of juvenile chum salmon on the Sanriku Coast before and after the tsunami. The carbon stable isotope after the tsunami was higher than it was before, despite no difference in the nitrogen stable isotope. This result supports that 1) the tsunami caused carbon enrichment in the coastal ecosystem because of the churning of sludge, and that 2) juvenile chum salmon did not change their trophic level after the tsunami (Fig. 2). Minegishi et al. (2019) demonstrated the temporal-spatial change in the distribution of environmental DNA of juvenile chum salmon in the Otsuchi Bay. Juveniles were distributed throughout the bay from January to early June with two peaks (March and May) during periods of outmigration to other bays. On the Sanriku Coast, juvenile chum salmon dominantly fed on Themisto japonica during the offshore migration period (Kaeriyama 1986). Yamada et al. (2019) examined feeding ecology of juvenile chum salmon and clarified that 1) juveniles dominantly preyed on Neocalanus plumchrus and Themisto japonica from 2013-2015, however, 2) they fed primarily on decapod larvae in 2016 with very few Themisto japonica found in their stomachs. In the spring of 2016, the Oyashio cold current was very weak and left the Sanriku Coast in May.

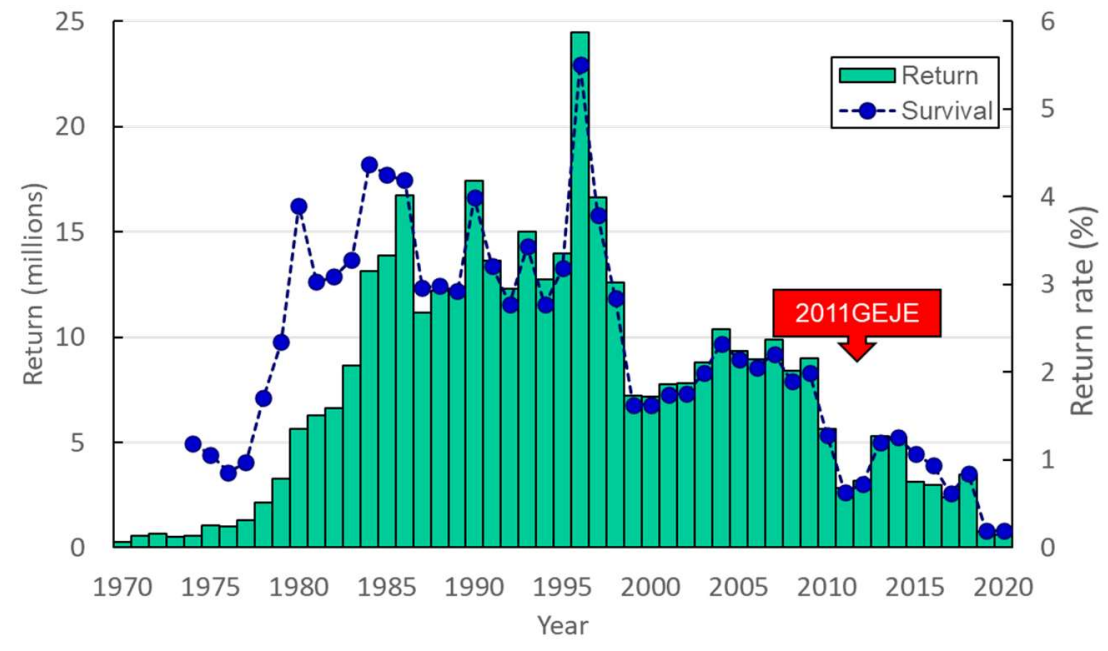

Fig. 3. Annual changes in return and return rate of chum salmon in the Iwate Prefecture.

Unfortunately, the return of chum salmon to the Sanriku Coast has continued to decline, even after the GEJE, despite damaged facilities and the salmon hatchery regime quickly recovering after the tsunami. After peaking in the 1990s, chum salmon return has been declining year-by-year and decreased to below a million individuals in 2019-2020 (Fig. 3). In this century, the sea surface temperature (SST) in spring showed an increasing trend (Fig. $4 \mathrm{~A}$ ) and in the recent quarter century, the SST increased $0.95^{\circ} \mathrm{C}$ in March, $1.13^{\circ} \mathrm{C}$ in April, $1.40^{\circ} \mathrm{C}$ in May, and $1.58^{\circ} \mathrm{C}$ in June (Fig. 4B). Juvenile chum salmon stay on the Sanriku Coast from March until the SST reaches 
$12.5^{\circ} \mathrm{C}$, before migrating offshore (Kaeriyama 1986 ); however, this stay-duration has been decreasing in recent years (Fig. 4C).

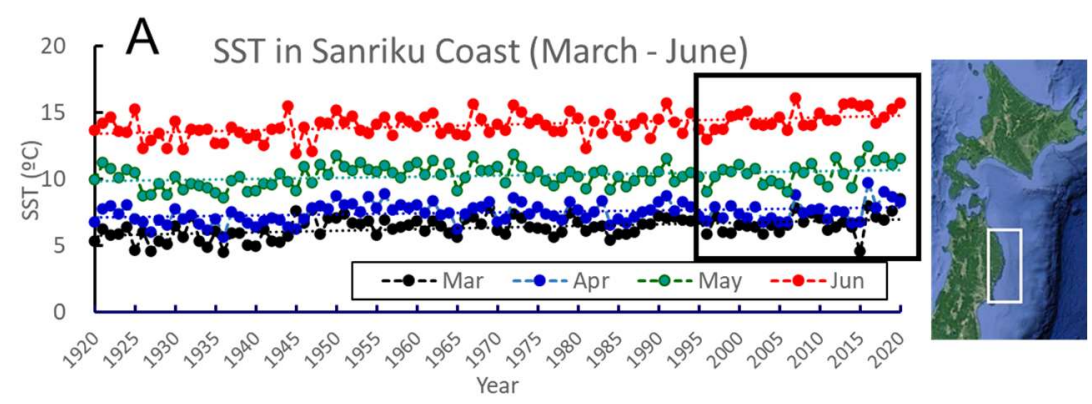

Fig. 4. Temporal change in spring sea surface temperature (SST) and stayduration of juvenile chum salmon on the Sanriku Coast. A: 1920-2020, B: 19952020, C: Duration of juvenile chum salmon stay on the Sanriku Coast.
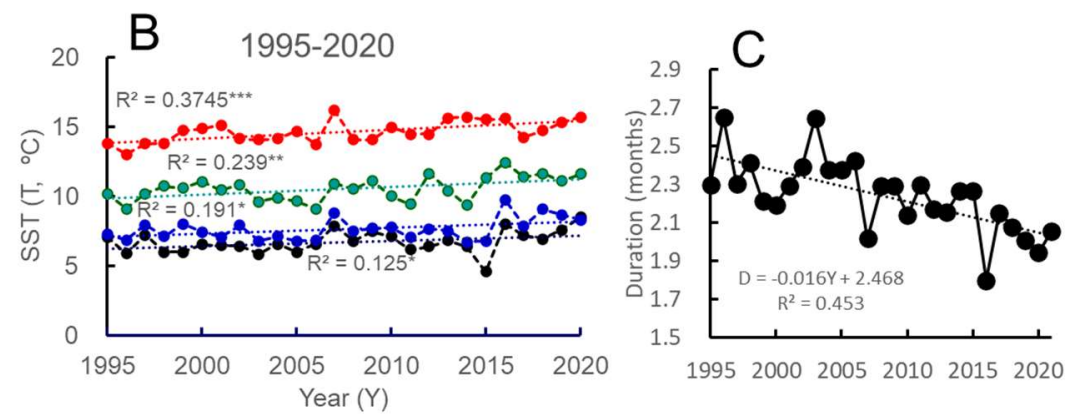

Chum salmon form a mark on their scales when juveniles migrate from the Sanriku Coast to offshore habitat at 8-14 cm in fork length (Fig. 5). Therefore, we can estimate the body size of a juvenile at offshore migration by measuring from the focus to the mark on the scale of an adult salmon, using the scale back-calculation. Figure. 6 demonstrates the temporal changes in estimated fork length (FL) anomaly at offshore migration, return rate, and the duration of coastal stay for juvenile chum salmon on the Sanriku Coast. The FL, duration, and return rate showed declining trends over time. The relationship between FL and return rate, and the relationship between FL and duration indicated significant positive correlations $(p<0.01)$, respectively. These facts suggest that juvenile salmon could not grow sufficiently by the offshore migration period due to the shortened stay-duration year by year, resulting in a decline in return rate of the Sanriku salmon (Kaeriyama 2019). We revealed temporal changes in estimated FL at age-1 Ishikari and Tsugaruishi River populations and return rates of Hokkaido and Iwate Prefecture chum salmon. Both FL and return rate increased after the 1980s, peaked in the late 1990s, and then began to decline after the early 2000s. The relationship between FL and return rate of both populations indicated significant correlations (Fig. 7). This suggests that global warming had a positive effect on Japanese chum salmon in the 1990s (Kaeriyama et al. 2014), but would have a negative impact on them since the mid-2000s.

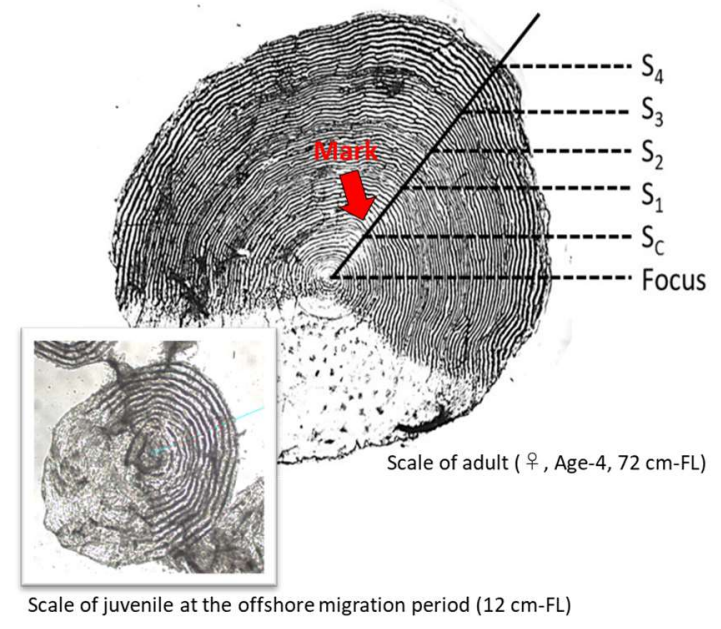

Fig. 5. Estimation of fork length of juvenile chum salmon at the period of offshore migration using the scale back calculation. Chum salmon form a mark on their scales at the period of offshore migration from the Sanriku Coast. 

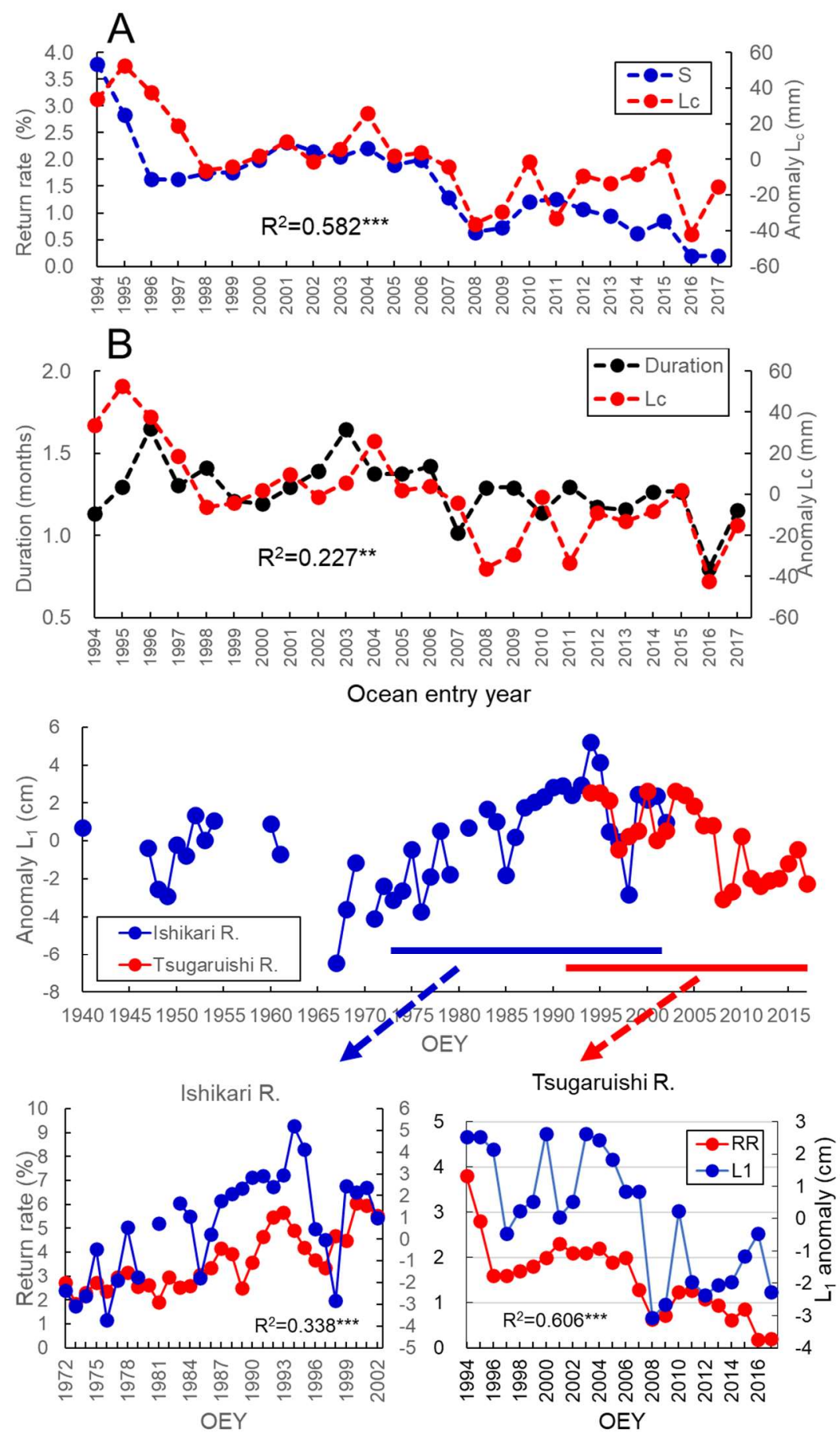

In general, larger juveniles precede the offshore migration period. On the Sanriku Coast, large juveniles (10$14 \mathrm{~cm}$ in FL) migrate offshore in advance while taking an optimal foraging strategy in May. Small juveniles (8 cm in FL) passively migrate offshore after late May, so they escape from the warm current (Kaeriyama 1986). We define these migration patterns as the active migration (AM) and the passive migration (PM), respectively. The temporal change in the offshore migration pattern of juvenile chum salmon in the Sanriku Coast since the 2000s (Fig. 8) indicated the following:

1) The period of offshore-migration has been reduced; AM juveniles have decreased and have disappeared after June.

2) The PM juveniles tended to accelerate the time of offshore migration. 
3) Dominant prey Themisto japonica also decreased or disappeared in the stomachs of juveniles after June.

These results suggest that juvenile survival rate would decline because of a missing migration route to Hokkaido or the Okhotsk Sea, and a lack of sufficient growth due to global warming (Kaeriyama and Urabe 2018).

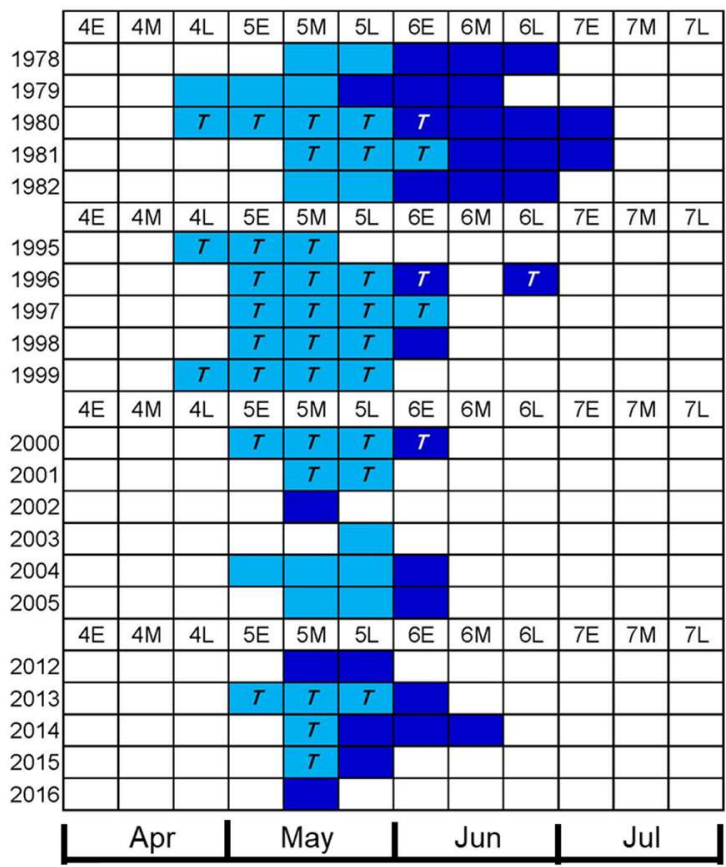

1978-1982: Kaeriyama (1986), 1995-2005: Hokkaido Salmon Hatchery (1996-1997), National Salmon Resources Center (1998-2006), 20122016: Iwate Prefecture (unpublished data)
Fig. 8. Temporal change in the offshore migration pattern of juvenile chum salmon on the Sanriku Coast. $\approx$ : the offshore migration period of the large AM; $\mathbf{m}$ : the offshore migration period of the small PM; $T$ : the appearance period of dominant prey Themisto japonica in stomach of juvenile chum salmon.

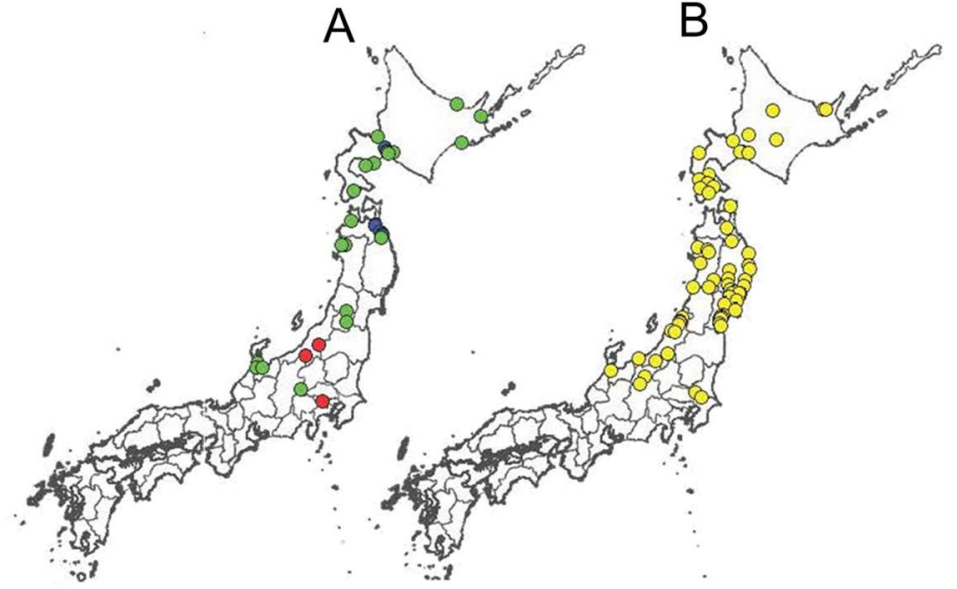

Fig. 9. The distribution of chum salmon remains in the Jomon Period. A: From the Incipient to the Early periods (16-5.5 kyr BP) • Incipient Period (16-12 kyr BP): 3 remains; $\bullet$ Initial Period (12-7 kyr BP): 5 remains; • Early Period (7-5.5 kyr BP): 22 remains. B: From the Middle to the Last periods (5.5-2.8 kyr BP): 67 remains.

We examined more than 130 thousand reports of the Jomon archaeological site (https://sitereports.nabunken.go.jp/ja) in order to evaluate the historical distribution pattern of chum salmon in Japan. Chum salmon were widely distributed throughout northern Japan since the middle Jomon period (5.5-2.8 thousand years ago; 67 remains). In the Incipient Jomon period (16-12 thousand years ago), relicts of chum salmon were discovered in Tokyo and Nagano Prefecture (three remains). On the other hand, in the Initial and Early Jomon periods (12-5.5 thousand years ago), chum salmon disappeared on the Pacific Ocean side of northern Honshu. However, contrary to the evidence (Ishida et al. 2001) so far, they were clearly distributed from Aomori to Toyama prefectures on the Japan Sea side (15 remains) as well as Hokkaido in these periods (Fig. 9). According to the historical change in the isotopic temperature of the ice core at the Dome Fuji of East Antarctica, since 350 thousand years ago the global temperature from the mid-Initial to the Early Jomon periods was about $2^{\circ} \mathrm{C}$ higher than at 
present (Watanabe et al. 2003). The Kuroshio Current strongly flowed north without the meander. These periods were called the "Jomon transgression" (Yamada 2019). In the last century, the global mean temperature has already increased about one degree Celsius and the current situation of chum salmon is approaching that of the Jomon transgression period in Japan.

- Goals

\section{Conservation \& Use}

- Conservation and recovery of wild salmon

- Innovation of salmon fisheries \& hatchery stocking

- Zoning between wild and hatchery salmon

2. Research \& Monitoring: Interaction between aquatic ecosystems \& salmon

- Climate change (e.g., Global warming, Regime-shift): sea \& freshwater ecosystems

- Change in aquatic ecosystem affecting the life history \& population dynamics of salmon

\section{Restoration \& resilience for wild salmon and river ecosystem}

- Restoration for impoverished river ecosystem

- Resilience of wild salmon

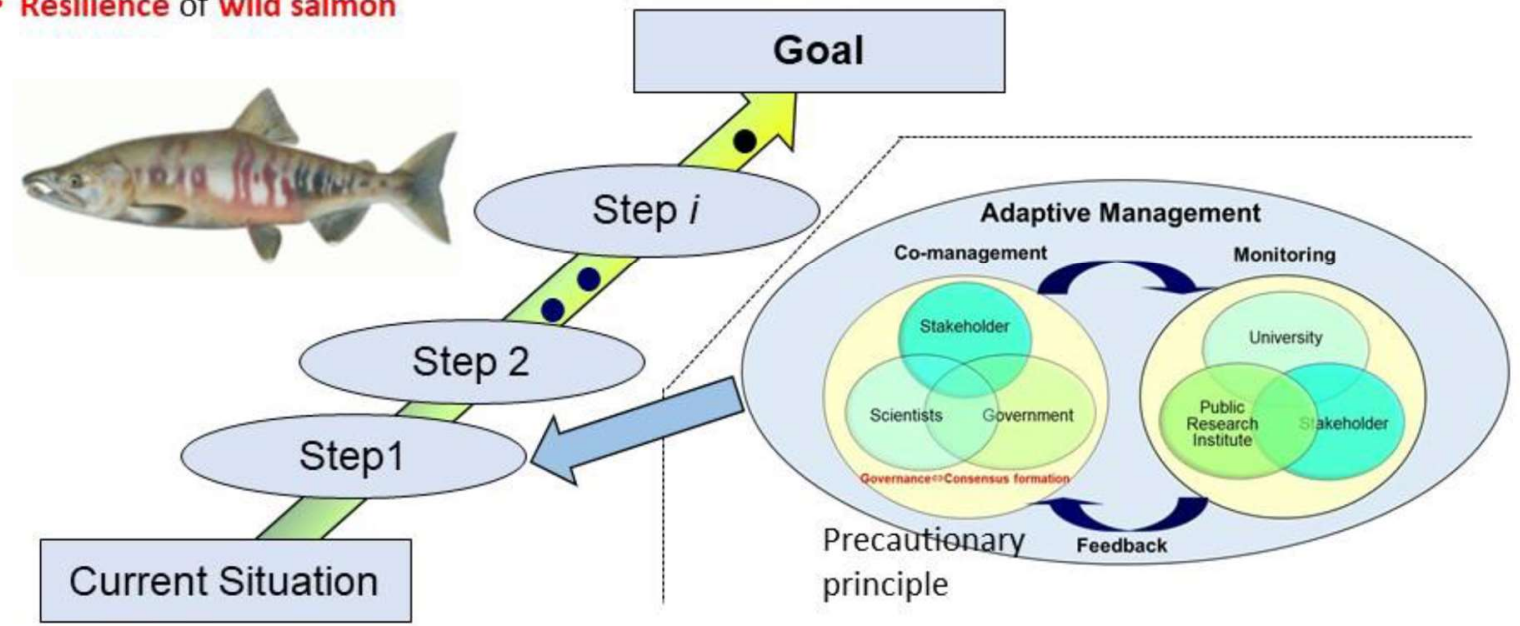

Fig. 10. Sustainable conservation management for chum salmon in Japan under the warming climate.

Under a changing climate we need to establish the "sustainable conservation management for chum salmon," based on a "back-casting approach" in Japan (Fig. 10). We should (1) set the final goal based on a sufficient analysis of the current situation, and (2) step up to the goal with adaptive management and the precautionary principle. We have three final goals: (1) how to conserve and use salmon, (2) how to carry out the research and monitor for interaction between aquatic ecosystems and salmon, and (3) how to restore and resilience for wild salmon and river ecosystems.

\section{REFERENCES}

Ishida, Y., T. Hariu, J. Yamashiro, S. McKinnell, T. Matsuda, and H. Kaneko. 2001. Archeological evidence of Pacific salmon distribution in northern Japan and implications for future global warming. Prog. Oceanogr. 49: $539-550$.

Kaeriyama, M. 1986. Ecological study on early life of the chum salmon, Oncorhynchus keta (Walbaum). Rep. Sci. Hokkaido Salmon Hatchery 40: 31-92. (In Japanese with English abstract)

Kaeriyama, M. 2019. Sustainable conservation and use of chum salmon under warming climate and changing ocean conditions. N. Pac. Anadr. Fish Comm. Tech. Rep. 15: 109-112. (Available at https://npafc.org)

Kaeriyama, M., and Y. Urabe. 2018. Global warming effect for migration route of Japanese chum salmon. N. Pac. Anadr. Fish Comm. Tech. Rep. 11: 91-95. (Available at https://npafc.org)

Kaeriyama, M., H. Seo, and Y. Qin. 2014. Effect of global warming on the life history and population dynamics of Japanese chum salmon. Fish. Sci. 80: 251-260. 
Minegishi, Y., M.K. Wong, T. Kanbe, H. Araki, T. Kashiwabara, M. Ijichi, K. Kogure, S. Hyodo. 2019. Spatiotemporal distribution of juvenile chum salmon in Otsuchi Bay, Iwate, Japan, inferred from environmental DNA. PLoS One 14: e0222052.

Qin, Y., G. Ogawa, Y. Shimizu, K. Yamane, and M. Kaeriyama. 2016. Early ocean life history of juvenile chum salmon Oncorhynchus keta populations in the Iwate coastal ecosystem after the Great Tohoku Earthquake and tsunami. In Marine ecosystem after Great East Japan Earthquake in 2011: Our knowledge acquired by TEAMS. Edited by K. Kogure, M. Hirose, H. Kitazato, and A. Kijima. Tokai University Press, Tokyo. pp. $111-112$.

Seo, H., H. Kudo, and M. Kaeriyama. 2011. Long-term climate-related changes in somatic growth and population dynamics of Hokkaido chum salmon. Environ. Biol. Fish. 90: 131-142.

Watanabe, O., J. Jouzel, S. Johnsen, F. Parrenin, and H. Shoji. 2003. Homogeneous climate variability across East Antarctica over the past three glacial cycles. Nature 422: 509-512.

Yamada, Y. 2019. History of Jomon period. Kodansha, Tokyo. 325 pp. (In Japanese)

Yamada, Y., K. Sasaki, K. Yamane, M. Yatsuya, Y. Shimizu, Y. Nagakura, T. Kurokawa, and H. Nikaido. 2019. The utilization of cold-water zooplankton as prey for chum salmon fry (Oncorhynchus keta) in Yamada Bay, Iwate, Pacific coast of northern Japan. Reg. Stud. Mar. Sci. 29: 1-9. 